\title{
Article
}

\section{Understanding interpersonal relationships and psychopathy}

Mooney, Robyn, Ireland, Jane Louise and Lewis, Michael

Available at http://clok.uclan.ac.uk/28331/

Mooney, Robyn, Ireland, Jane Louise ORCID: 0000-0002-5117-5930 and Lewis, Michael ORCID: 0000-0001-5567-3569 (2019) Understanding interpersonal relationships and psychopathy. Journal of Forensic Psychiatry and Psychology, 30 (4). pp. 658-685. ISSN 1478-9949

It is advisable to refer to the publisher's version if you intend to cite from the work. http://dx.doi.org/10.1080/14789949.2019.1615102

For more information about UCLan's research in this area go to

http://www.uclan.ac.uk/researchgroups/ and search for <name of research Group>.

For information about Research generally at UCLan please go to http://www.uclan.ac.uk/research/

All outputs in CLoK are protected by Intellectual Property Rights law, including Copyright law. Copyright, IPR and Moral Rights for the works on this site are retained by the individual authors and/or other copyright owners. Terms and conditions for use of this material are defined in the policies page.

\section{CLoK}

Central Lancashire online Knowledge www.clok.uclan.ac.uk

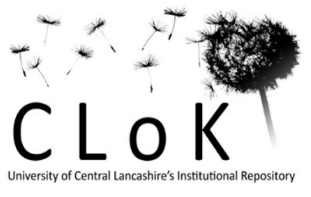


Understanding Interpersonal Relationships and Psychopathy

\author{
Robyn Mooney*, Jane L. Ireland ${ }^{1}$, Michael Lewis \\ *Edge Hill University and Ashworth Research Centre, Mersey Care NHS Trust, UK \\ University of Central Lancashire, Preston, UK and Ashworth Research Centre, Mersey Care \\ NHS Trust, UK.
}

${ }^{1}$ Corresponding author. Email: JLIreland1@uclan.ac.uk; University of Central Lancashire, Preston, UK, PR1 2HE; Tel: +44 1772201201 . 


\begin{abstract}
Although psychopathy is widely recognised for its importance in forensic and criminal justice settings, the range of interpersonal relationships that are experienced and engaged in by individuals with psychopathy is understudied. A Rapid Evidence Assessment (Study 1) examined what is known empirically about the nature and quality of relationships for individuals with psychopathy. Affective, Cognitive and Lifestyle Assessment (ACL) interviews and genograms were then analysed in conjunction with Psychopathy Checklist: Screening Version (PCL:SV) scores to explore the extent, nature, and quality of interpersonal relationships in student and forensic psychiatric samples (Study 2). Quantitative data indicated that total psychopathy score predicted a smaller number of positive interpersonal relationships. Findings regarding Factors 1 and 2 and numbers of positive and negative interpersonal relationships varied between samples. Qualitative analyses demonstrated that psychopathic participants used less positive descriptors than non-psychopathic participants when discussing their interpersonal relationships. Findings are examined with regards to implications for future research.
\end{abstract}




\section{Understanding Interpersonal Relationships and Psychopathy}

Although individuals with psychopathy comprise less than $1 \%$ of the general population (Blair, Mitchel, \& Clair, 2005; Coid, Yang, Ullrich, Roberts, \& Hare, 2009; Neumann \& Hare, 2008), their representation is much higher in correctional settings: it is estimated that $11 \%$ of forensic psychiatric patients and 8-25\% of prison inmates have psychopathy (Coid, Yang, Ullrich, Roberts, Moran, et al., 2009; Hare, 2003). These individuals are responsible for approximately half of all serious criminal offences (Hare, 2003). Because individuals with psychopathy commit a disproportionate number of criminal offences, understanding this challenging population and the range of their relationships with others is of significant interest to forensic mental health professionals. Despite this, the breadth of interpersonal relationships of psychopathic individuals remains poorly understood by researchers and clinicians alike.

Psychopathy, first defined by Cleckley (1941), is often disaggregated into different subtypes, such as primary and secondary. According to Karpman, while the two subtypes are phenotypically similar (Poythress \& Skeem, 2006), their aetiologies differ. Primary psychopathy is said to originate in a dispositional absence of conscience (Karpman, 1948), while secondary psychopathy is believed to be a product of one's environment and early experiences. Not all researchers embrace the primary vs. secondary classification of psychopathy, however. In addition, there remains some diversity in opinion concerning the origins and development of psychopathy. Regardless, there is consensus for a social and neural basis to psychopathy, with the latter having received increasing interest across the past two decades; arguments have been made for a strong genetic/prenatal component, whilst also accounting for the impact of negative developmental experiences, such as abuse (Blair, Peschardt, Dudhani, Mitchell \& Pine, 2006) 
and the influence of social-environmental variables (Blair, 2013). There is now broad acceptance that the emotional dysfunction element is a product of genetic components, including a lack of [impulse] control (Blair et al, 2006), with callous unemotional traits appearing to be particularly influenced (Viding, Frick \& Plomin, 2007). There is also an increasing consensus that the processes underlying deficits in regulation in children with conduct problems may differ if callous-unemotional traits are indicated (Frick et al, 2003). Viding, Blair, Moffitt and Plomin (2005), for example, noted how if callous-unemotional traits are high and combined with antisocial behaviour then a strong hereditary component is indicated. More recent reviews of the research argue, however, for a moderate-to-strong heritability component and account more for a role for protective environmental factors in countering the risk of hereditary (Viding \& McCrory, 2018). Collectively, this research has led to a view that a neural system dysfunction argument for the developmental basis of psychopathy is undeniable, with findings narrowing to account for the role specifically of uncaring/callous dimensions and deficits in distress recognition as factors seemingly being accounted for entirely by shared genetic influences as opposed to environmental factors (Moore et al, 2019), whilst continuing to accept a role for protective environmental factors (Viding \& McCrory, 2018). The specific behavioural sequelae of this neural dysfunction are becoming of increasing interest (Blair, 2015), with behavioural sequelae including the manifestation of interpersonal functioning, the focus of the current paper.

Regarding assessment, at present, the most extensively validated, researched, and utilised diagnostic instrument for psychopathy is Hare's $(1991,2003)$ Psychopathy Checklist-Revised (PCL-R). As a result, although other classifications have been proposed (e.g. Cooke \& Michie, 2001), Hare's conceptualisation of the construct dominates in the literature (e.g. Harpur, Hare, \& Hakstian, 1989; Kosson, Forth, Steuerwald, \& Kirkhart, 1997). According to Hare (1991, 2003), 
psychopathy comprises two factors. Factor 1 refers to interpersonal and affective deficits, incorporating traits such as interpersonal manipulation, lack of empathy, shallow affect, and egotism; meanwhile, Factor 2 encompasses aspects of a chronically antisocial lifestyle, such as impulsivity, irresponsibility, and criminal versatility. These two factors correspond roughly with primary (Factor 1) and secondary (Factor 2) psychopathy. While Factor 2 is more strongly implicated in criminality than Factor 1 (Kennealy, Skeem, Walters, \& Camp, 2010), Factor 1 is often said to represent the core of psychopathic personality (Blackburn, 1998; Harpur et al., 1989) and draws upon the importance of emotional dysfunction as an intrinsic component of the disorder. It is for this reason, namely emotional dysfunction, that a neural basis has been increasingly considered and accepted (Blair et al, 2006; Blair, 2015; Moore et al, 2019; Viding et al, 2005; Viding et al 2007). Other theories are also accounted for, however, in the development of psychopathy, such as attachment and interpersonal theory, and could complement neurological/genetic explanations by attending to the social-environment where development is taking place (Blair, 2013), including accounting for protective factors of the environment (Viding \& McCrory, 2018). The latter could potentially have a more notable influence in relation to the anti-social behaviour component of psychopathy (Factor 1) in the absence of high callousunemotional traits (Factor 1) (Viding, Blair, Moffitt \& Plomin, 2005).

In consideration of the environment, several studies have found a link between psychopathy and poor attachment. In an undergraduate and community sample, Christian, Sellbom, and Wilkinson (2018) observed that participants who scored high on affective psychopathic traits (which fall under Factor 1) had fewer bonds with peers and family, although the effect size was small. Frodi, Dernevik, Sepa, Philipson, and Bragesjo (2001) examined mental representations of early attachment relationships in a sample of 24 Swedish psychopathic 
offenders, finding that none of their participants could be considered securely attached, and most tended to dismiss their attachment-related experiences. Meanwhile, using a self-report measure of trait psychopathy, Mack and colleagues (2011) found a positive relationship between secondary psychopathy and each type of insecure attachment (i.e., anxious and avoidant) in an American undergraduate sample. In this study, participants with high scores on primary psychopathy tended to score high on both anxious and avoidant attachment simultaneously. Conradi and colleagues (2016) also found a positive correlation between attachment avoidance and both Factor 1 and Factor 2 trait psychopathy in an undergraduate sample. Finally, Blanchard and Lyons (2016) found that, in male participants, primary psychopathic traits were related to attachment avoidance, while secondary psychopathic traits were linked to attachment anxiety. Conversely, in female participants, primary psychopathic traits were associated with both types of insecure attachment, while secondary psychopathic traits were not predicted by any attachment style.

While the results of these studies are far from unanimous, it has been consistently concluded that there is a link between psychopathy or psychopathic traits and insecure attachment, lack of attachment bonds, or adverse childhood experiences involving one's primary caregiver (Christian et al., 2018; Frodi et al., 2001), with such experiences equally noted as potentially important environmental variables in research focusing on neural pathways to psychopathy (e.g. Blair et al, 2006, 2013). The most prominent trend that has emerged from the literature is the finding that Factor 1 is associated with attachment avoidance (Blanchard \& Lyons, 2016; Conradi et al., 2016), while Factor 2 is linked to attachment anxiety (Blanchard \& Lyons, 2016; Mack et al., 2011). However, some studies have found a link between Factor 1 and attachment anxiety (Blanchard \& Lyons, 2016) or between Factor 2 and attachment avoidance 
(Conradi et al., 2016; Mack et al., 2011). Therefore, the precise nature of the association between psychopathy and attachment remains unclear. Equally, there is increasing recognition that as a concept attachment is being revisited. There are, for example, arguments posited that the attachment described at infancy cannot be considered the same as at adolescence and beyond owing to different measures being utilised. In addition, it is argued that there needs to be a distinction drawn between attachment as a dyadic feature versus an individual feature, and that attachment insecurity is not as closely associated with later psychopathology as once argued. Indeed, the concept of attachment insecurity has been perhaps increasingly replaced by the concept of attachment disorganisation (Rutter, 2014). It would not, however, appear that the literature base on attachment and psychopathy has yet caught up with these developments in the conceptualisation of attachment, including attempting to integrate with neurobiological research on psychopathy development. The same can be said of interpersonal theory although this potentially offers a greater understanding of the dynamics in interaction that could be occurring more currently and perhaps therefore represents a clearer example of the behavioural sequalae of neural dysfunction referred to by Blair (2015).

First conceptualised by Sullivan (1953) and Leary (1957), interpersonal theory suggests that all interpersonal interactions are driven by two orthogonal dimensions of behaviour. The dimension of power and control is anchored on one end by dominance and on the other by submission; meanwhile, the dimension of affiliation is anchored by hostility and nurturance (Blackburn, 1998). These four anchors form the coordinates of what is known as the interpersonal circle. The quadrants of the interpersonal circle can be used to describe the interpersonal behaviour of individuals with personality disorders, with the interpersonal behaviour conceptualised as a developed style and thus becoming more trait-focused. Indeed, 
according to Sullivan (1953), when studying psychopathology, focus should be on interpersonal dynamics rather than socially deviant behaviour (Blackburn, 1998). According to interpersonal theory, personality disorders represent dysfunctional interpersonal styles that can be described in terms of the interpersonal circle. These interpersonal styles are underpinned by maladaptive internal working models that lead the individual to hold certain expectations about social interactions and relationships. These expectations can function as self-fulfilling prophecies when one's approach to an interaction serves to elicit the precise response the individual was expecting to receive (Carson, 1979).

As noted previously, Factor 1 is believed to be more fundamental to the core of psychopathy than Factor 2 (Blackburn, 1998; Harpur et al., 1989), and for this reason has been more closely associated with the genetic component of psychopathy owing to the callousunemotional component (Viding, Blair, Moffitt \& Plomin, 2005; Moore et al, 2019) forming part of Factor 1. Interpersonal deviance is said to lie at the heart of psychopathy (Draycott, Askari, \& Kirkpatrick, 2011), and these features can be detected by others in interactions lasting as short as five seconds (Fowler, Lilienfeld, \& Patrick, 2009). Accordingly, Blackburn (1998) believes that this unique personality disorder is best described in relation to the interpersonal circle. Existing research indicates that the part of the circle that describes the interpersonal style of psychopathic individuals is the hostile-dominant quadrant, as psychopathy manifests as a combination of hostility and dominance in interpersonal interactions (Blackburn, 1998; Harpur, Hart, \& Hare, 2002; Rauthmann \& Kolar, 2013).

Blackburn (1998) asserts that, according to interpersonal theory, psychopathic individuals' inability to form secure attachment bonds with others leads to the development of internal working models that cause the individual to perceive or expect hostility from others. 
This causes them to approach interpersonal interactions in a hostile and dominant manner, which then elicits hostile responses from others. These hostile responses confirm the psychopathic individual's expectations and function to prevent cognitive dissonance from occurring. However, this proposed pattern remains understudied.

In comparison to the vast number of published articles on the topic of psychopathy, relatively few studies have examined the nature of relationships in individuals who score high on psychopathy. Saltaris (2002) proposed a pathway whereby conduct problems, temperament, and insecure attachments in psychopathic individuals lead to "aversive interpersonal tendencies" (p. 744) that contribute to negative interpersonal interactions that begin in childhood and persist into adulthood. Other studies have found a negative association between psychopathy and relationship quality. In a community sample of British men, Ullrich, Farrington, and Coid (2008) found a significant relationship between the interpersonal domain of psychopathy and a history of unsuccessful intimate relationships. Similarly, Love and Holder (2016) found that high levels of trait psychopathy were negatively associated with overall relationship quality in an undergraduate sample.

Few studies have examined psychopathic individuals' subjective perceptions of their interpersonal relationships. The current research addresses this knowledge gap by exploring how psychopathic individuals perceive the extent, nature, and quality of their interpersonal relationships, and how this varies according to Factor 1, Factor 2, and total psychopathy scores. It examines this across two studies; Study 1 comprised a Rapid Evidence Assessment (REA) of the literature (Barends, Rousseau, \& Briner, 2017; Thomas, Newman, and Oliver, 2013) to explore what is known empirically about the nature and quality of relationships for individuals with psychopathy. This was followed by Study 2, which used qualitative and quantitative 
methods to compare the extent, nature, and quality of interpersonal relationships in male samples of university students and adult forensic psychiatric patients. Study 2 had several hypotheses:

1.) Psychopathy scores (total score, Factor 1 , and Factor 2) would be higher for forensic psychiatric patients than students (Coid, Yang, Ullrich, Roberts, Moran, et al., 2009; Hare, 2003; Neumann \& Hare, 2008).

2.) For both patients and students, increased total psychopathy scores would predict fewer interpersonal relationships (Blackburn et al., 2005; Christian et al., 2018; Frodi et al., 2001), and this would hold regardless of whether a relationship was described by the participant as positive or negative.

3.) For both patients and students, increased Factor 1 and 2 scores would predict fewer interpersonal relationships overall, including across positive and negative relationships.

4.) Participants in both samples who score above the threshold for psychopathy would (a) describe their relationships less positively and (b) use positive relationship descriptors less frequently than participants who score below this threshold (Love \& Holder, 2016; Ullrich et al., 2008).

\section{Study 1}

\section{Method}

The REA examined abstracts of published journal articles from MedLine, Science Direct, PsycINFO, PsycARTICLES and Google Scholar databases using the search terms psychopathy AND interpersonal AND relationships. To be considered for inclusion, articles needed to be available to the researcher in full-text. No restrictions were placed on year or country of origin, but only easily accessible, English-language studies were considered for inclusion. Exclusion criteria were (a) duplicate articles and (b) articles focusing on child or adolescent populations. 
No hand-searches were conducted since this was a RAE. The initial search yielded 170 results. Of these, 157 were available to the researcher in full-text, and 134 were published in English. After screening these 134 abstracts for relevance, 16 eligible articles were selected for inclusion.

\section{Results}

Appendix A details the articles included in this review. Twelve of the included studies utilised community samples, five included student samples, three focused on forensic psychiatric patients, and two examined prison samples. Nine (40.9\%) of the studies included in the REA were based in the United States. Six (27.2\%) utilised samples from the United Kingdom. Three used Croatian samples, two $(9.1 \%)$ used samples from the Netherlands, and one each (4.5\%) used samples from Australia, Austria, Belgium, and Germany. Sixteen included studies that measured trait/subclinical psychopathy through the use of self-report instruments, six (27\%) focused instead on clinical psychopathy as measured by the PCL-R (Hare, 1991, 2003), Psychopathy Checklist: Screening Version (PCL:SV; Hart, Cox, \& Hare, 1995), or a comparable clinical instrument.

Themes. Five themes were extracted from the 16 eligible articles that discussed psychopathy and interpersonal relationships. Five articles (31\%; Blackburn, Logan, Renwick, \& Donnelly, 2005; Fix \& Fix, 2015; Jonason, Duineveld, \& Middleton, 2015; Rauthmann, 2011; Sherman \& Lynam, 2017;) discussed the interpersonal traits of psychopathic individuals; four (25\%; Brewer, Bennett, Davidson, Ireen, Phipps, Stewart-Wilkes, \& Wilson, 2018; Christian, Sellbom, \& Wilkinson, 2017; Kardum, Hudek-Knezevic, Gračanin, \& Mehic, 2017; Massar, Winters, Lenz, \& Jonason, 2017) focused on the interpersonal relationships of psychopathic individuals; three (19\%: Blackburn \& Maybury, 1985; Lobbestael, Arntz, Voncken, \& Potegal, 2017; Reidy, Wilson, Sloan, Cohn, Smart, \& Zeichner, 2013) examined psychopathy and 
interpersonal behaviour; two (12.5\%: Declercq, Willemsen, Audenaert, \& Verhaeghe, 2012;

Walsh, Swogger, \& Kosson, 2009) explored psychopathy and interpersonal aggression; and two (12.5\%; Iyican \& Babcock, 2018; Mager, Bresin, \& Verona, 2014) discussed psychopathy and intimate partner violence.

Theme 1: Interpersonal traits. In an analysis of higher-order personality dimensions, Blackburn, Logan, Renwick, \& Donnelly (2005) provided support for the notion that, as described by interpersonal theory, psychopathic individuals have a hostile and dominant interpersonal style that is characterised by high agency and low communal motivation.

Several studies examined the interpersonal traits of students and members of the community in relation to their scores on trait psychopathy. Their results indicate that trait psychopathy is positively associated with low levels of social communion and a higher likelihood of discounting the value of interpersonal closeness (Sherman \& Lynam, 2017), as well as being positively associated with an exchange orientation (defined as the prioritisation of one's own interests over those of the group) and negatively associated with a communal orientation (Jonason, Duineveld, \& Middleton, 2015). Jonason and colleagues (2015) speculate that low levels of communalism may be evolutionarily advantageous in terms of securing one's own survival and reproductive fitness, and psychopathy may therefore be adaptive in nature. Overall, these findings indicate that individuals who score high on trait psychopathy tend to be unmotivated at forming and maintaining close relationships with others.

Rauthmann (2011) found that trait psychopathy was associated with both 'acquisitive' self-monitoring (characterised by an extraverted interpersonal style and desire for social acceptance) and 'protective' self-monitoring (an interpersonal style characterised by fear of social rejection). The author speculates that Factor 1 may be linked to acquisitive self- 
monitoring, while protective self-monitoring may correspond to Factor 2. In this study, trait psychopathy was also associated with interpersonal perceptiveness. Thus, individuals who score high on trait psychopathy may be adept at perceiving others' reactions and adjusting their own interpersonal behaviour in order to maximise success at interpersonal manipulation (Rauthmann, 2011). This assertion was supported by the results of Fix and Fix (2015). In their study, undergraduate students who scored higher on trait psychopathy reported lower levels of care for others and emotional understanding, but higher levels of interpersonal functioning. The authors conclude that interpersonal style may differentiate between so-called 'successful' and 'unsuccessful' psychopaths, whereby 'successful psychopaths' possess a heightened understanding of interpersonal relations.

Theme 2: Interpersonal relationships. These studies examined the nature and quality of psychopathic individual's interpersonal relationships in regards to attachment styles. Christian, Sellbom, and Wilkinson (2017) found that Factor 2 was associated with anxious attachment, while Factor 1 was associated with avoidant attachment. They concluded that the interpersonal relationships of individuals who score high on Factor 2 are likely to be characterised by fear of rejection, boundary problems, and demanding behaviour. In contrast, the relationships of individuals who score high on Factor 1 are more likely to be characterised by dismissiveness, cynicism, and intimacy avoidance. Similarly, Brewer and colleagues (2018) discovered that those who scored high on Factor 1 were less likely to desire close personal relationships, less likely to find them personally rewarding, and more likely to prefer non-exclusive relationships. Like Christian et al. (2017), these authors found that high Factor 2 scores predicted attachment anxiety in romantic relationships. However, in this study, both Factors of trait psychopathy predicted attachment avoidance. 
In a series of three studies Kardum, Hudek-Knezevic, Gračanin, \& Mehic (2017) found that couples who scored high on the interpersonal facet of psychopathy tended to seek out partners similar to themselves in regards to interpersonal manipulation. High psychopathy scores in men predicted negative relationship quality for both the men and women in these relationships. Meanwhile, for women, similarity in terms of interpersonal manipulation scores predicted higher relationship quality. The authors concluded that when women are higher on interpersonal manipulation than their partner, they are likely to exhibit high levels of proactivity and control. As a result, their male partners may perceive them as resourceful and committed to the relationship; thus, divergence in this socially problematic trait may actually contribute to relationship maintenance.

Finally, one study (Massar, Winters, Lenz, \& Jonason, 2017) found that both Factors of trait psychopathy were associated with jealousy induction, while Factor 2 was uniquely associated with the experience of jealousy. They concluded that individuals who score high on trait psychopathy respond to relationship threat with maladaptive maintenance strategies: those who score high on Factor 1 induce jealousy in a calculated way in order to get revenge or gain power over their partner, while those who score high on Factor 2 do so in order to repair their self-esteem or 'test' their partner, likely as a result of insecurity about themselves or the relationship.

Theme 3: Interpersonal behaviour. In their study of male forensic psychiatric patients, Blackburn and Maybury (1985) found that two psychopathic personality profiles emerged. However, with the exception of extraversion, these two categories fail to correspond with the 'primary' vs. 'secondary' classification of psychopathy. 
A Dutch study (Lobbestael, Arntz, Voncken, \& Potegal, 2017) examined psychopathic dominance through two experimental lab tasks. They discovered that during an interview-based confrontation, participants who scored high on Factor 1 tended to increase their own dominance display when confronted by a highly dominant interviewer. The authors interpreted this finding through the lens of interpersonal theory, speculating that some participants were mimicking the dominant behaviour of the interviewer. Meanwhile, in a spatial task, participants who scored low on Factor 2 preferred to keep dominant interviewers at a greater distance from themselves than submissive interviewers. Interestingly, participants who scored high on Factor 2 allowed the dominant interviewer to approach more closely, demonstrating a low level of spatial defensiveness. In line with Jonason et al. (2015), Lobbestael and colleagues propose that this discrepancy regarding Factor 2 scores and spatial behaviour may indicate the adaptive strategy of submissive individuals who minimise threat to oneself by keeping dominant individuals at a distance.

Reidy and colleagues (2013) discovered that the activation of anger during a hypothetical interpersonal conflict was positively associated with Factor 2 and negatively associated with Factor 1. This finding indicates that the interpersonal aspects of psychopathy decrease one's risk of becoming angry and reactive during interpersonal conflicts. This conclusion adds nuance to Rauthmann's (2011) and Fix and Fix's (2015) assertions about the interpersonal skills of psychopathic individuals, highlighting that these interpersonal skills may be the result of high Factor 1 scores rather than high levels of trait psychopathy overall.

Theme 4: Interpersonal aggression. Walsh and colleagues (2009) found that psychopathy was associated with the use of instrumental violence, and this link was strongest for Factor 1. Similarly, Declercq, Willemsen, Audenaert, and Verhaeghe (2012) found that Factor 1 
was associated with goal-directed predatory aggression and negatively associated with emotional arousal during the commission of a violent offence. Thus, instrumental violence may be one of the interpersonal manipulation tactics exhibited by psychopathic individuals, and predatory violence may be a function of one's interpersonal style, which is often characterised by power, control, and egotism in high Factor 1 scorers.

Theme 5: Intimate partner violence (IPV). Mager and colleagues (2014) found that both Factors were linked to higher likelihood of IPV perpetration in their sample, but the association between Factor 1 and IPV was stronger in men. Meanwhile, Iyican and Babcock (2018) found that male Factor 1 score was associated with perpetration of IPV, but these authors found no association between IPV perpetration and male Factor 2 score. Thus, it appears that the relationship between psychopathy and IPV is stronger in men than women, and Factor 1 plays a unique role. Iyican and Babcock (2018) proposed that Factor 1 is more strongly implicated in IPV perpetration than Factor 2 because of the element of interpersonal dominance that is inherent to Factor 1.

Overall, the results of this REA provide support for the conceptualisation of psychopathy within an interpersonal framework and the importance of regarding psychopathy as a multidimensional construct characterised by two distinct Factors that manifest in different phenotypic traits and behaviours. However, the observed patterns in the published literature indicate that there is a need for studies which (a) explore a broader range of interpersonal relationships in psychopathic individuals; (b) focus more on the clinical conceptualisation of the disorder; (c) make use of institutionalised (forensic) samples; and (d) employ implicit, qualitative measures that lack the constraints and potential pitfalls of quantitative self-report scales. Study 2 attempts to address many of these gaps, as it uses genograms to capture a range of interpersonal 
relationships in both institutionalised and noninstitutionalised samples, linking these findings to scores on a measure of clinical psychopathy.

On the basis of insight gleaned from this REA, additional predictions were formulated for Study 2. It was anticipated that, for both patients and students, increased Factor 1 scores would predict fewer intimate relationships (Christian et al., 2017) and fewer close relationships (Brewer et al., 2018). It was further hypothesised that increased Factor 1 scores would predict a greater number of intimate relationships characterised by aggression on behalf of the participant (Iyican \& Babcock, 2018; Mager et al., 2014), and that this pattern would be found in both patient and student samples.

\section{Study 2}

\section{Method}

Participants. Fifty students and 40 adult forensic psychiatric patients participated, all male. Students were recruited at a university in Northwest England and ranged in age from 18 to 36 years $(M=22.64, S D=4.47)$. The patient sample was recruited at a high secure forensic psychiatric hospital in Northwest England. Patients were not approached for recruitment if they resided on a high dependency ward, were in seclusion, or presented with a neurocognitive impairment. Sampled patients ranged in age from 22 to 60 years $(M=40.15, S D=9.96)$.

Materials. Psychopathy Checklist: Screening Version (PCL:SV; Hart et al., 1995). The PCL:SV is an abbreviated screening version of the Psychopathy Checklist: Revised (PCL-R; Hare, 2003). Designed for use in both civil and forensic settings, the PCL:SV comprises 12 items that derive from the PCL-R and capture psychopathy in terms of the overall construct as well as Factors 1 and 2 separately. Each item is scored on a three-point scale ranging from 0 (does not apply) to 2 (definitely applies). Total scores of 13 and above are said to indicate the possible 
presence of psychopathy (Hart et al., 1995). Initial validations of the PCL:SV across 11 samples yielded acceptable internal consistency for the total scale (mean $\alpha=.84$ ), Factor 1 subscale (mean $\alpha=.81$ ), and Factor 2 subscale (mean $\alpha=.75$ ) (Hart et al., 1995).

Affect, Cognitive and Lifestyle Assessment (ACL; Ireland \& Ireland, 2014). The ACL is an integrated measure that was designed to explore in depth the specific affective, cognitive, and lifestyle functioning challenges that characterise psychopathy (Ireland, Ireland, Lewis, Jones, \& Keeley, 2016). Included within the ACL is a detailed exploration of relationships through the use of genograms, which was the element considered for the current study. Traditionally used for gaining and processing information pertaining to family genealogy, genograms are clinical tools that can be used by counsellors and therapists (Papadopoulos, Bor, \& Stanion, 1997). Genograms can provide detail about the dynamics of a relationship that is richer in meaning than responses based on more restrictive quantitative methods. The current study is the first to capitalise on this implicit approach to provide insight into how psychopathic individuals perceive their own relationships.

\section{Procedure}

Ethical approval was obtained from the University of Central Lancashire and the NHS. For the clinical sample, Responsible Clinicians provided written consent before any patients were approached for participation in the study. All participants signed written consent forms before participating. Participants completed the ACL assessment and were assessed for psychopathy using the PCL:SV semi-structured interview and, in the case of forensic patients, a file review. Following a debriefing, all participants were paid $£ 10$ for their time. The current study used a previously unanalysed component of the ACL assessments (pertaining to relationships and the genograms). Other aspects of the dataset (e.g. validation of the ACL) are 
published elsewhere ${ }^{2}$. In addition to the completed genograms, eight groups of previously unanalysed ACL interview questions were chosen for inclusion in this study on the basis of their link to the research findings of the literature analysed in Study 1. These items were: 1.) How would you describe emotions? What do emotions mean to you? 2.) What is a positive emotion? List some examples; 3.) What is a negative emotion? List some examples; 4.) How easy do you find it to take advantage of or to get 'one over' on someone? Give an example of when you have done this. If you have never taken advantage of someone, what stopped you? 5.) When you lose your temper, how do you tend to react? How often do you lose your temper? what would others say? 6.) The term 'survival of the fittest' describes the importance of securing your survival against all odds, no matter what the cost to others. To what extent do you agree with this? What situations may it apply to? 7.) How would you describe your relationships with others? (e.g. friends, family, work colleagues); 8.) Who are the most important people in your life at the moment and why?

Responses were recorded in abbreviated written form by ML and the first author, RM, transcribed these written responses electronically prior to analysis.

\section{Results}

Psychopathy scores (means and standard deviations) for patients and students are provided in Table 1.

<INSERT TABLE 1 HERE>

PCL:SV scores. A one-way Welch ANOVA was conducted to assess whether forensic psychiatric patients demonstrated significantly higher PCL:SV total scores than students. The results of this analysis indicate that patients did score higher on the PCL:SV $(\mathrm{M}=14.7, \mathrm{SD}=$

\footnotetext{
${ }^{2}$ Ireland et al., 2016
} 
4.31) than students ( $M=2.34, \mathrm{SD}=2.69)$, and this difference was statistically significant, Welch's $F(1,62.321)=250.71, \mathrm{p}<.001$. Twenty-eight $(70 \%)$ of the patients scored above the threshold for possible psychopathy (score of 13 or higher on the PCL:SV); none (0\%) of the students met this threshold. In order to examine differences between the two samples on the PCL:SV subscales (Factor 1 and Factor 2), a one-way multivariate analysis of variance (MANOVA) was conducted. Results of the MANOVA indicated that forensic psychiatric patients scored significantly higher than students on Factor $1(M=6.37, S D=2.69$ and $M=1.12$, $S D=1.96$, respectively; Pillai's trace $=.78 ; F(1,89)=115.23, p<.001 ;$ partial $\left.\eta^{2}=.57\right)$.

Patients also scored significantly higher than students on PCL:SV Factor $2(M=8.33, S D=2.71$ and $M=1.24, S D=1.33$, respectively; Pillai's trace $=.78 ; F(1,89)=262.54, p<.001 ;$ partial $\eta^{2}$ $=.75)$.

Genograms. Genograms from the ACL assessment were converted into quantitative data representing the extent and quality of participants' interpersonal relationships. An abridged example of the genogram instructions is indicated in Figure 1. Genogram data were coded according to total number of relationships depicted, the type of relationship (i.e. family, intimate partner, friend, or colleague), and whether the relationships were labelled as positive ('close') or negative ('distant', 'cut-off', 'conflictual', or 'enmeshed'). Genogram labels also indicated whether relationships involved aggression from the participant, aggression from the other person in the relationship, or both.

\section{$<$ INSERT FIGURE 1 HERE >}

These data were then analysed in conjunction with PCL:SV scores. Because one patient's genogram responses represented an extreme univariate outlier by reporting 120 friends, their data were adjusted to ensure they still represented an extreme response while guarding against a 
skewed dataset. Means and standard deviations for the number and nature of each type of relationship drawn by participants are depicted in Table 2.

\section{<INSERT TABLE 2 HERE>}

A series of linear regressions were conducted to assess whether higher total scores on the PCL:SV predicted a smaller overall number of interpersonal relationships, a smaller number of positive relationships, and a smaller number of negative relationships. Students and patients were examined separately.

For the student sample, increased PCL:SV total score predicted a smaller number of positive relationships, $F(1,48)=4.92, p<0.05$; Predictor, $t=-2.22, p<0.05, B=-.37, S E=.17$, $\beta=-.31$; predicting $9 \%$ of the variance $\left(\mathrm{R}^{2}=.09\right.$, Adjusted $\left.\mathrm{R}^{2}=.07\right)$ and a greater number of negative relationships, $F(1,48)=9.78, p<0.01$; Predictor, $t=3.13, p<0.01, B=.53, S E=.17$, $\beta=.41$; predicting $17 \%$ of the variance $\left(\mathrm{R}^{2}=.17\right.$, Adjusted $\left.\mathrm{R}^{2}=.15\right)$. However, total psychopathy score failed to predict total number of interpersonal relationships in the student sample, $F(1,48)=1.08$, $n s$.

For the patient sample, increased PCL:SV total score predicted a smaller number of positive relationships, $F(1,38)=11.97, p<0.001$; Predictor, $t=-3.46, p<0.001, B=-.46, S E=$ $.13, \beta=-.49$; predicting $24 \%$ of the variance $\left(\mathrm{R}^{2}=.24\right.$, Adjusted $\left.\mathrm{R}^{2}=.22\right)$. However, PCL:SV total score did not predict total number of interpersonal relationships $(F(1,38)=3.79$, $n s)$ or number of negative relationships $(F(1,38)=.16, n s)$.

A series of multiple regression analyses assessed whether increased PCL:SV Factor 1 and Factor 2 scores predicted a smaller number of interpersonal relationships overall, positive relationships, and negative relationships. Again, patients and students were examined separately. For the student sample, only the model examining PCL:SV Factors 1 and 2 against the number 
of negative relationships was significant, $F(2,47)=6.04, p<0.01$; predicting $20 \%$ of the variance $\left(\mathrm{R}^{2}=.2\right.$, Adjusted $\left.\mathrm{R}^{2}=.17\right)$, with higher Factor 2 scores predicting a greater number of negative interpersonal relationships, $t=2.77, p<0.01, B=.99, S E=.36, \beta=.38$. The contribution of Factor 1 to the model was not significant, $t=1.17, n s$. Neither Factor 1 nor Factor 2 scores predicted total number of interpersonal relationships $(F(2,47)=1.54, n s$; Factor $1, t=-.24, n s ;$ Factor $2, t=1.73, n s)$, or number of positive relationships $(F(2,47)=2.36, n s$; Factor $1, t=-1.39, n s ;$ Factor $2, t=-1.17, n s)$. For the patient sample, only the model examining increased PCL:SV Factor 1 and 2 scores against number of positive relationships was significant, $F(2,37)=6.53, p<0.01$; predicting $26 \%$ of the variance $\left(\mathrm{R}^{2}=.26\right.$, Adjusted $\left.\mathrm{R}^{2}=.22\right)$, with higher psychopathy Factor 2 scores predicting a smaller number of positive interpersonal relationships, $t=-2.92, p<0.01, B=-.65, S E=.22, \beta=-.43$. Factor 1 did not contribute significantly to the model, $t=-1.25, n s$. Factor 1 and Factor 2 scores failed to predict total number of interpersonal relationships $(F(2,37)=1.88, n s$; Factor $1, t=-.95, n s$; Factor 2, $t=-$ $1.37, n s)$, or number of negative relationships $(F(2,37)=.3, n s$; Factor $1, t=-.29, n s$; Factor $2, t$ $=.78, n s)$.

Linear regressions were also conducted to explore the associations between Factor 1 score and avoidance of intimacy, lack of desire for close relationships, and perpetration of intimate partner violence. For patients, increased PCL:SV Factor 1 score significantly predicted a smaller number of intimate relationships, $F(1,38)=5.38, p<0.05$; Predictor, $t=-2.32, p<0.05$, $B=-.24, S E=.1, \beta=-.35$; predicting $12 \%$ of the variance $\left(\mathrm{R}^{2}=.12\right.$, Adjusted $\left.\mathrm{R}^{2}=.1\right)$. However, Factor 1 score failed to predict number of close relationships $(F(1,38)=1.6, n s)$ or number of intimate relationships characterised by aggression on behalf of the participant $(F(1$, $38)=.6, n s)$. For the student sample, Factor 1 score failed to predict number of intimate 
relationships $(F(1,48)=.59, n s)$, number of close relationships $(F(1,48)=2.18, n s)$, or number of intimate relationships characterised by aggression from the participant $(F(1,48)=.79, n s)$.

ACL interview responses. For analyses utilising total psychopathy score, the total sample was split into two groups: those who reached the threshold for 'possible psychopathy' according to the PCL:SV (i.e. score of 13 or above), and those who did not. For analyses focusing on the Factor 1 or Factor 2 score specifically, median splits were conducted on the student and patient samples separately. Chi-square tests for association and independent samples $t$-tests were then conducted between the psychopathy group ("possibly psychopathic" and "not psychopathic") and ACL response categories that corresponded to some of the findings of studies included in the REA (Study 1). Two of the ACL interview questions asked participants to (1) describe their interpersonal relationships with others and (2) indicate the most important people in their life and why. The responses to these two ACL questions are depicted in Table 3. <INSERT TABLE 3 HERE>

Regarding relationship quality, $t$-tests indicated that significantly more participants in the not psychopathic group described their relationships with others as ' $\operatorname{good}$ ', $t(1,66.26)=2.97, p<$ .01 and 'close', $t(1,80.3)=2.31, p<.05$, than the participants in the possibly psychopathic group. Participants in the non-psychopathic group mentioned friends $(t(1,88)=4.64, p<.001)$ and intimate partners $(t(1,83.87)=3.7, p<.001)$ significantly more frequently than those in the possibly psychopathic group. The following relationship descriptors arose significantly more frequently in the non-psychopathic group than the possibly psychopathic group: support ( $t(1$, $62.41)=2.78, p<.01)$, history $(t(1,61)=3.01, p<.01)$, stability $(t(1,88)=2.95, p<.01)$, trust $(t(1,61)=2.56, p<.05)$, and connection $(t(1,61)=2.05, p<.05)$ 


\section{Discussion}

Study 1 identified five key themes in the literature regarding the interpersonal interactions and relationships of psychopathic individuals: (1) traits, (2) relationships, (3) behaviour, (4) interpersonal aggression, and (5) intimate partner violence. The results of this Rapid Evidence Assessment (REA) demonstrated that although there are a vast number of published articles about psychopathy and its symptoms, including those relating to interpersonal relationships, there is less focused on how those with psychopathy perceive the quality and nature of their relationships, particularly in terms of the positive and negatives of these relationships. Thus, the relationships of psychopathic individuals, with regards to how they experience and perceive them, remains relatively poorly understood, with an absence of effort to link this perception and/or experience with other potentially driving factors, namely a neural basis (Blair et al, 2006; Blair, 2015; Viding et al, 2005; Moore et al, 2019).

The majority $(81 \%)$ of the studies included in the REA utilised noninstitutionalised samples. Relatedly, $69 \%$ of the included articles focused on a subclinical conceptualisation of the construct. However, psychopathy is first and foremost a clinical construct; thus, the lack of available studies exploring the relationships of institutionalised samples and/or individuals who meet the threshold for a clinical diagnosis represents a significant shortcoming in our current level of knowledge surrounding this topic. While clinical and trait psychopathy appear to be similar, forensic patients and prisoners differ significantly from students and individuals in the community, and the two kinds of samples should not be conflated. For instance, the criminal histories of institutionalised samples often include interpersonal or intimate partner violence. This may imply that maladaptive interpersonal styles are more problematic for this population than for noninstitutionalised individuals. More research is needed that explores the nature and 
quality of relationships for institutionalised samples and/or those who score above the diagnostic threshold for clinical psychopathy in comparison to noninstitutionalised samples and/or those who score below the clinical threshold. This research could provide insight into how these populations differ and why some psychopathic individuals become criminal offenders while others do not. This could easily be extended to capture a role for a neural (genetic/prenatal) basis underlying these differences (Blair et al, 2006; Blair, 2013; Blair, 2015; Viding et al, 2005, 2007; Moore et al, 2019), since it is already recognised that it is the combination of high callousunemotional traits and conduct challenges that have a potentially different developmental pathway in terms of neural dysfunction to those with just callous-unemotional traits alone (Viding at et, 2005). Furthermore, because the leading conceptualisation of psychopathy (Hare, 1991, 2003) is one that describes psychopathic individuals as inherently prone to criminality, the validity of research that only examines non-offender samples or measures psychopathy using self-report instruments remains questionable, particularly if the findings are to be generalised to offender samples or individuals who meet a clinical diagnostic threshold.

Another knowledge gap that emerged from the REA is underpinned by the fact that all of the included studies were conducted in Western countries. All but one of the articles originated in North America or Europe, and the remaining study was Australian. Psychopathy may manifest differently in non-Western cultures; accordingly, more research is needed that examines the relationships of psychopathic individuals that reside outside these geographical areas.

Although the focus of Study 1 was the relationships of psychopathic individuals, many of the articles yielded by the search terms examined the interpersonal behaviour of this population in short-term interactions. This interesting result may represent another significant manner in which our knowledge about these relationships is lacking. While relationships are considered to 
last days, weeks, or years and require a certain level of interpersonal effort to maintain, interactions are much more transient and endure only for minutes or perhaps hours. Thus, findings about psychopathic individuals' interpersonal behaviour in short-term interactions may not provide us with sufficient information about the characteristics of their relationships. While interpersonal theory asserts that interpersonal styles are enduring and consistent patterns of interacting with others (Blackburn, 1998), how these patterns impact on relationships over time remains unclear.

Some studies included in the REA did examine lasting relationships for psychopathic individuals (e.g. Iyican \& Babcock, 2018; Kardum et al., 2017; Massar et al., 2017). However, the measures used in these studies were quantitative in nature (e.g. Experiences in Close Relationships Revised Questionnaire; Fraley, Waller, \& Brennan, 2000), focusing on a narrow range of relationships and defining aspects of these relationships through the use of predetermined boundaries and characteristics. Furthermore, these quantitative measures tend to adopt a transparent, self-report approach. Because psychopathy includes such behavioural traits as manipulation and deceit (Hare, 1991, 2003), self-report instruments that use explicit questioning tactics are vulnerable to invalid responses from participants who score high on psychopathy. This highlights the need for more implicit, qualitative approaches to assessing the interpersonal relationships of psychopathic individuals. Genograms may represent one such approach.

Study 2 addressed the gaps and shortcomings identified in the REA by quantitatively and qualitatively exploring the extent, nature, and quality of interpersonal relationships in psychopathy. Use of the ACL genograms allowed for unique insight into how possibly psychopathic individuals perceive their own relationships. Genograms may be particularly 
effective with populations who are not typically forthcoming in verbal interviews: while some of the ACL interview responses utilised in Study 2 were quite abbreviated in nature, the genogram responses were consistently rich across all participants.

As anticipated, forensic psychiatric patients scored significantly higher than students on psychopathy as measured by the PCL:SV (total score, Factor 1, and Factor 2). The hypotheses that increased PCL:SV total score would predict a smaller number of overall, positive, and negative interpersonal relationships was partially supported. For both patients and students, increased total psychopathy score predicted fewer positive relationships. However, contrary to what was predicted, increased total psychopathy score also predicted a greater number of negative relationships in the student sample. Upon deeper analysis, this unexpected finding appeared to be due to the influence of Factor 2, as Factor 1 did not have an effect on the number of negative relationships, while Factor 2 predicted a greater number of negative relationships. Meanwhile, as anticipated, increased Factor 2 scores predicted a smaller number of positive relationships in the patient sample. Factor 1 had no effect on number of overall, positive, or negative relationships for this group, but increased Factor 1 scores did predict a smaller number of intimate relationships for the patient group (no relationship was found between Factor 1 score and number of intimate relationships in the student sample).

Contrary to what was hypothesised, the quantitative data did not support the hypothesis that increased Factor 1 scores would predict a smaller number of close relationships. However, the qualitative data showed that participants who scored above the threshold for possible psychopathy (total score) were less likely to describe their relationships as 'good' or 'close' than those who scored below the PCL:SV threshold for possible psychopathy. This discrepancy may indicate that the Factor 2 score has a stronger effect on the quality and extent of one's 
interpersonal relationships; alternatively, the qualitative nature of the ACL interview may be more successful than genograms at capturing these aspects of interpersonal relationships.

Regarding the nature of interpersonal relationships in psychopathic individuals, the qualitative analyses indicated that, as predicted, participants who scored above the threshold for possible psychopathy used positively influenced descriptors (support, stability, history, connection, and trust) significantly less frequently than participants who are not psychopathic. The lower relative frequency of these descriptors in the possibly psychopathic group are consistent with the assertion of Love and Holder (2016) that psychopathy is associated with poor relationship quality. This finding is also supported by historical conceptualisations of psychopathy (e.g. Cleckley, 1941; Hare, 1991, 2003), which emphasise the parasitic, manipulative, impulsive, and irresponsible manner in which these individuals move through life while failing to form meaningful long-term relationships.

Tentative support has emerged in the literature regarding the associations between Factor 1 and attachment avoidance (Blanchard \& Lyons, 2016; Brewer et al., 2018; Christian et al., 2017; Conradi et al., 2016) and Factor 2 and attachment anxiety (Blanchard \& Lyons, 2016; Brewer et al., 2018; Christian et al., 2017; Mack et al., 2011). In the current study, ACL genograms and interview data did demonstrate a link between psychopathy and lack of attachment bonds. Furthermore, the finding that Factor 1 was associated with fewer intimate relationships and Factor 2 to poorer quality relationships, provide additional support for the associations that have been proposed in the literature, as they demonstrate that individuals who score high on psychopathy tend to have relationships that are more negative both in quantity and quality. If these findings are interpreted through the lens of attachment theory, it can be speculated that those who score high on Factor 1 may tend to avoid intimacy (Christian et al., 
2017), while those who score high on Factor 2 may behave in such a way that the quality of their interpersonal relationships is negatively impacted (e.g. relationship jealousy and subsequent over-compensatory behaviours) (Massar et al., 2017). In keeping with developments in the attachment field, where the concept of attachment insecurity is being increasingly critiqued (Rutter, 2014), it would also suggest attachment disorganisation may be of relevance to consider, certainly as a direction for future research. It also perhaps points to more crucial issues not captured in the current study, such as the neural basis to psychopathy, including genetics and/or prenatal experiences, which are potentially influencing how those with psychopathy are relating to others, regardless of attachment history. Indeed, it is the behavioural sequela of the neural system (Blair, 2015), of which interpersonal functioning forms part, that is perhaps proving of more interest. This is a direction for future research to consider and one where the integration of neural and interpersonal assessment across populations becomes of particular value, particularly that which attends more readily to the differing role of callous unemotional traits (Factor 1) versus antisocial behaviour components (Factor 2) (Viding et al, 2005, 2007; Moore et al, 2019; Frick et al, 2003). To advance the area even further such research could also explore concurrently the potentially moderating impact of protective factors in the environment (Viding \& McCrory, 2018).

The results of Study 2 lends some support to an interpersonal theory perspective of psychopathy, which places this personality type in the hostile-dominant quadrant of the interpersonal circle. Psychopathic individuals are said to perceive and expect hostility from others, subsequently behaving in a way that elicits this reaction from the other person (Carson, 1979). This interpersonal style represents a pattern through which all interactions and relationships are approached. Thus, interpersonal theory infers that psychopathic individuals 
experience relationships that are few in quantity and poor in quality. Overall, the findings of Study 2 support this notion in the finding that participants who are possibly psychopathic have fewer positive relationships and fewer intimate relationships, and they use positive relationship descriptors with less frequency than non-psychopathic participants.

\section{Limitations}

This research is not without limitations. Although the results provide support for the findings of previous studies linking psychopathy with poor relationship quality (e.g. Love \& Holder, 2016; Ullrich, et al., 2008), without being able to compare participants' self-reported perceptions of their relationships to the perceptions of the other members of these relationship dyads, it is not possible to ascertain whether the participants' perceptions align with those of the other person or if they diverge from how the other person views the relationship. In addition, the ACL genogram approach is relatively new and under-researched, particularly with the challenging population of forensic psychiatric patients. It is unclear whether all participants fully understood the instructions for the genogram task, and it is not possible to determine whether the number of relationships they recorded was accurate. Their responses may represent inaccurate reporting - for instance, due to fatigue or disinterest. Furthermore, across both samples, participants may have drawn genograms for the same person across multiple categories (e.g. 'friend' and 'colleague'; 'colleague' and 'intimate partner'), which could invalidate to a certain extent the number of relationships depicted. There are also obvious challenges in drawing comparisons between student and forensic psychiatric populations. They are presented here as two divergent groups and not as comparison groups per se. The problems in trying to compare to very distinct groups is thus acknowledged. 
Study 2 attempted to address some of the shortcomings identified by Study 1 by including the use of an instrument designed to measure clinical psychopathy (PCL:SV) rather than reliance on a self-report measure of trait (subclinical) psychopathy. However, the PCL:SV is a screening tool, not a diagnostic instrument. Therefore, the grouping of participants into 'possibly psychopathic' and 'not psychopathic' groups represents a tentative approach to classifying participants and cannot be regarded as a definitive judgement. Equally, the study did not capture emotional dysfunction as a potential facilitating or mediating factor that could explain interpersonal interactions. Whilst recognising emotional dysfunction as a central element of psychopathy, and as a variable salient to the promotion of good quality interpersonal relationships, it fell beyond the scope of the current research to consider. It does, nevertheless, suggest that a useful direction for future research would be to build on the current findings by capturing emotional dysfunction, perhaps by exploring processing abilities and deficiencies and how these could potentially relate to the psychopathy-interpersonal relationship dimension. An obvious direction would be to incorporate neurological and hereditability assessments to try and capture the influence of such functioning on interpersonal style as well as the acknowledgement of related genetic and prenatal differences and how these could be impacting on the core emotional components of psychopathy versus the behavioural components, of which interpersonal style forms part. The current study also did not account for hereditability in the relationships reported other than noting family as a relationship example; thus, were the quality of these relationships, as described by the participants, influenced by the personality characteristics (e.g. callous-unemotional) of the family member they were engaging with? Callous-unemotional traits have a strong genetic loading and it could have been one means of ascertaining this aspect (Viding et al, 2005; Frick et al, 2003; Moore et al, 2019). 


\section{Conclusions}

This research has identified and attempted to address some of the shortcomings that are present in the existing literature on the topic of psychopathy, including the reliance on quantitative measures of subclinical psychopathy in non-forensic samples and the tendency to disregard psychopathic participants' own perceptions of their interpersonal relationships. The results of Study 2 provide support for conceptualisations of psychopathy driven by attachment theory and interpersonal theory, as well as the use of qualitative measures such as the ACL assessment (Ireland \& Ireland, 2014) to explore this poorly understood construct. Future research should build on these findings by administering the ACL to other forensic populations, in conjunction with the use of an established diagnostic instrument such as the PCL-R (Hare, 1991, 2003) and the incorporation of neurological/genetic assessment. Through the repetition of this nuanced approach to examining psychopathy, researchers may gain much-needed additional insight into the interpersonal aspects of psychopathy. By better understanding the interpersonal traits, relationships of psychopathic individuals and pre-existing genetic contributions, targeted interventions may be designed and implemented in order to improve the interpersonal behaviour and relationships of this challenging forensic population, whilst also remaining realistic in terms of how much change be promoted.

\section{References}

Barends, E., Rousseau, D. M., \& Briner, R. B. (Eds). (2017). CEBMa Guideline for Rapid Evidence Assessments in Management and Organizations, Version 1.0. Amsterdam: Center for Evidence Based Management. Retrieved from https://www.cebma.org/wpcontent/uploads/CEBMa-REA-Guideline.pdf 
Blackburn, R. (1998). Psychopathy and personality disorder: Implications of interpersonal theory. In D. J. Cooke, A. E. Forth, \& R. D. Hare (Eds.), Psychopathy: Theory, research, and implications for society (pp. 269-302). Dordrecht, Netherlands: Kluwer Academic Publishers.

Blackburn, R., Logan, C., Renwick, S. J., \& Donnelly, J. P. (2005). Higher-order dimensions of personality disorder: Hierarchical structure and relationships with the Five-Factor Model, the Interpersonal Circle, and psychopathy. Journal of Personality Disorders, 19(6), 597623. doi: 10.1521/pedi.2005.19.6.597

Blackburn, R., \& Maybury, C. (1985). Identifying the psychopath: The relation of Cleckley's criteria to the interpersonal domain. Personality and Individual Differences, 6(3), 375386. doi: 10.1016/0191-8869(85)90062-5

Blair, J., Mitchel, D., \& Blair, K. (2005). The psychopath: Emotion and the brain. Malden, MA: Blackwell

Blair, J.R. J, Peschardt, K. S., Budhani, S., Mitchell, DGV., Pine, PS. (2006). The development of psychopathy, Journal of Child Psychology and Psychiatry, 47 (3 - 4). 262 - 276. doi.org/10.1111/j.1469-7610.2006.01596.x

Blair, J. R. J. (2013). The neurobiology of psychopathic traits in youths. Nature Reviews Neuroscience, 14 (11), 786. doi: 10.1038/nrn3577

Blair, J. R. J. (2015). Reward processing, functional connectivity, psychopathy and research domain criteria. Biological Psychiatry, 78(9), 592 - 593. doi: 10.106/j.biopsych.2015.08.014.

Blanchard, A., \& Lyons, M. (2016). Sex differences between primary and secondary 
psychopathy, parental bonding, and attachment style. Evolutionary Behavioral Sciences, 10(1), 56. doi: 10.1037/ebs0000065

Brewer, G., Bennett, C., Davidson, L., Ireen, A., Phipps, A., Stewart-Wilkes, D., \& Wilson, B. (2018). Dark Triad traits and romantic relationship attachment, accommodation, and control. Personality and Individual Differences, 120, 202-208. doi: 10.1016/j.paid.2017.09.008

Carson, R. C. (1979). Personality and exchange in developing relationships. In R. L. Burgess \& T. L. Huston (Eds.), Social exchange in developing relationships (pp. 247269). New York: Academic Press.

Christian, E., Sellbom, M., \& Wilkinson, R. B. (2017). Clarifying the associations between individual differences in general attachment styles and psychopathy. Personality Disorders: Theory, Research, and Treatment, 8(4), 329-339. doi: 10.1037/per0000206

Christian, E., Sellbom, M., \& Wilkinson, R. B. (2018). Is psychopathy associated with deficits in bonding in an adult noninstitutionalized sample? The association between intimate social network size, attachment behavior, and psychopathy. Journal of Social and Personal Relationships, 1-19. doi: 10.1177/0265407518775239.

Cleckley, H. (1941). The mask of sanity. St. Louis, MO: Mosby.

Coid, J., Yang, M., Ullrich, S., Roberts, A., \& Hare, R. D. (2009). Prevalence and correlates of psychopathic traits in the household population of Great Britain. International Journal of Law and Psychiatry, 32(2), 65-73. doi: 10.1016/j.ijlp.2009.01.002

Coid, J., Yang, M., Ullrich, S., Roberts, A., Moran, P., Bebbington, P.,...Hare, R. (2009). Psychopathy among prisoners in England and Wales. International Journal of Law and Psychiatry, 32(3), 134-141. doi: 10.1016/j.ijlp.2009.02.008 
Conradi, H. J., Boertien, S. D., Cavus, H., \& Verschuere, B. (2016). Examining psychopathy from an attachment perspective: The role of fear of rejection and abandonment. Journal of Forensic Psychiatry \& Psychology, 27(1), 92-109. doi:

$10.1080 / 14789949.2015 .1077264$

Cooke, D. J., \& Michie, C. (2001). Refining the construct of psychopathy: Towards a hierarchical model. Psychological Assessment, 13(2), 171-188. doi:10.1037/10403590.13.2.171

Declercq, F., Willemsen, J., Audenaert, K., \& Verhaeghe, P. (2012). Psychopathy and predatory violence in homicide, violent, and sexual offences: Factor and facet relations. Legal and Criminological Psychology, 17, 59-74. doi: 10.1348/135532510X527722

Draycott, S. Askari, R., \& Kirkpatrick, T. (2011). Patterns and changes in psychopathic interpersonal behaviour in forensic inpatient treatment. Personality and Mental Health, 5, 200-208. doi: 10.1002/pmh.171

Fix, R. L., \& Fix, S. T. (2015). Trait psychopathy, emotional intelligence, and criminal thinking: Predicting illegal behavior among college students. International Journal of Law and Psychiatry, 42-43, 183-188. doi: 10.1016/j.ijlp.2015.08.024

Frick, P. J., Cornell, A. H., Bodin, S. D., Dane, H. E., Barry, C. T., \& Loney, B. R. (2003). Callous-unemotional traits and developmental pathways to severe conduct problems. Developmental psychology, 39(2), 246.

Fowler, K. A., Lilienfeld, S. O., \& Patrick, C. J. (2009). Detecting psychopathy from thin slices of behavior. Psychological Assessment, 21(1), 68-78. doi: 10.1037/a0014938

Fraley, R. C., Waller, N. G., \& Brennan, K. A. (2000). An item response theory analysis of self-report measures of adult attachment. Journal of Personality and Social Psychology, 
78, 350-365. doi: 10.1037/0022-3514.78.2.350.

Frodi, A., Dernevik, A. S., Sepa, A., Philipson, J., \& Bragesjo, M. (2001). Current attachment representations of incarcerated offenders varying in degree of psychopathy. Attachment \& Human Development, 3(3), 269-283. doi:

$10.1080 / 14616730110096889$

Hare, R. D. (1991). The Hare Psychopathy Checklist—Revised. Toronto, ON: Multi-Health Systems.

Hare, R. D. (2003). Manual for the Hare Psychopathy Checklist—Revised (2nd ed.). Toronto, ON: Multi-Health Systems.

Harpur, T. J., Hare, R. D., \& Hakstian, A. R. (1989). Two-factor conceptualization of psychopathy: Construct validity and assessment implications. Psychological Assessment, 1(1), 6-17. doi: 10.1037//1040-3590.1.1.6

Harpur, T. J., Hart, S. D., \& Hare, R. D. (2002). Personality of the psychopath. In P. T. Costa, Jr. \& T. A. Widiger (Eds.), Personality disorders and the five-factor model of personality (pp. 299-324). Washington, DC, US: American Psychological Association.

Hart, S. D., Cox, D. N., \& Hare, R. D. (1995). Manual for the screening version of the Psychopathy Checklist (PCL:SV). Toronto, ON: Multi-Health Systems.

Ireland, J. L., \& Ireland, C. A. (2014). Affective, Cognitive, and Lifestyle Assessment (ACL). UK: TIOFP and University of Central Lancashire.

Ireland, J. L., Ireland, C. A., Lewis, M., Jones, C., \& Keeley, S. (2016). Initial development of an implicit and explicit approach to assess psychopathy. International Journal of Law and Psychiatry, 46, 117-128. doi: 0.1016/j.ijlp.2016.02.008 
Iyican, S., Babcock, J. C. (2018). The relation between the two factors of psychopathy and intimate partner aggression. Journal of Aggression, Maltreatment \& Trauma, 27(2), 119130. doi: $10.1080 / 10926771.2017 .1334020$

Jonason, P. K., Duineveld, J. J., \& Middleton, J. P. (2015). Pathology, pseudopathology, and the Dark Triad of personality. Personality and Individual Differences, 78, 43-37. doi: 10.1016/j.paid.2015.01.028

Kardum, I., Hudek-Knezevic, J., Gračanin, A., \& Mehic, N. (2017). Assortative mating for psychopathy components and its effects on the relationship quality in intimate partners. Psychological Topics, 26, 211-239.

Karpman, B. (1948). The myth of the psychopathic personality. American Journal of Psychiatry, 104(9), 523-534. doi: 10.1176/appi.ajp.104.9.523

Kennealy, P. J., Skeem, J. L., Walters, G. D., \& Camp, J. (2010). Do core interpersonal and affective traits of PCL-R psychopathy interact with antisocial behavior and disinhibition to predict violence? Psychological Assessment, 22(3), 569-580. doi: $10.1037 / \mathrm{a} 0019618$

Kosson, D. S., Forth, A. E., Steuerwald, B. L., \& Kirkhart, K. J. (1997). A new method for assessing the interpersonal behavior of psychopathic individuals: Preliminary validation studies. Psychological Assessment, 9(2), 89-101. doi: 10.1037//10403590.9.2.89

Leary, T. (1957). Interpersonal diagnosis of personality. New York, NY: Ronald Press.

Lobbestael, J., Arntz, A., Voncken, M., \& Potegal, M. (2017, June 19). Responses to dominance challenge are a function of psychopathy level: A multimethod study. Personality Disorders: Theory, Research, and Treatment, 9 (4), 305-314. 
dx.doi.org/10.1037/per0000252

Love, A. B., Holder, M. D. (2016). Can romantic relationship quality mediate the relation between psychopathy and subjective well-being? Journal of Happiness Studies, 17, 24072429. doi: 10.1007/s10902-015-9700-2

Mack, T. D., Hackney, A. A., \& Pyle, M. (2011). The relationship between psychopathic traits and attachment behavior in a non-clinical population. Personality and Individual Differences, 51(5), 584-588. doi: 10.1016/j.paid.2011.05.019

Mager, K. L., Bresin, K., \& Verona, E. (2014). Gender, psychopathy factors, and intimate partner violence. Personality Disorders: Theory, Research, and Treatment, 5(3), 257267. doi: $10.1037 /$ per0000072

Massar, K., Winters, C. L., Lenz, S., \& Jonason, P. K. (2017). Green-eyed snakes: The associations between psychopathy, jealousy, and jealousy induction. Personality and Individual Differences, 115, 164-168. doi: 10.1016/j.paid.2016.01.055

Moore, A. A., Rappaport, L. M., Blair, R. J., Pine, D. S., Leibenluft, E., Brotman, M. A., ... \& Roberson- Nay, R. (2019). Genetic underpinnings of callous- unemotional traits and emotion recognition in children, adolescents, and emerging adults. Journal of child psychology and psychiatry.

Neumann, C. S., \& Hare, R. D. (2008). Psychopathic traits in a large community sample: Links to violence, alcohol use, and intelligence. Journal of Consulting and Clinical Psychology, 76(5), 893-899. doi: 10.1037/0022-006X.76.5.893

Papadopoulos, L., Bor, R., \& Stanion, P. (1997). Genograms in counselling practice: A review (part 1). Counselling Psychology Quarterly, 10(1), 17-28. doi:

$10.1080 / 09515079708251408$ 
Poythress, N. G., \& Skeem, J. L. (2006). Disaggregating psychopathy: Where and how to look for subtypes. In C. J. Patrick (Ed.), Handbook of psychopathy (pp. 172-192). New York, NY: The Guildford Press.

Rauthmann, J. F. (2011). Acquisitive or protective self-presentation of dark personalities? Associations among the Dark Triad and self-monitoring. Personality and Individual Differences, 51, 502-508. doi: 10.1016/j.paid.2011.05.008

Rauthmann, J. F., \& Kolar, G. P. (2013). Positioning the Dark Triad in the interpersonal circumplex: The friendly-dominant narcissist, hostile-submissive Machiavellian, and hostile-dominant psychopath? Personality and Individual Differences, 54, 622-627. doi: 10.1016/j.paid.2012.11.021

Reidy, D. E., Wilson, L. F., Sloan, C. A., Cohn, A. M., Smart, L. M., \& Zeichner, A. (2013). Psychopathic traits and men's anger response to interpersonal conflict: A pilot study. Personality and Individual Differences, 55, 957-961. doi: 10.1016/j.paid.2013.07.473

Rutter, M., (2014). Commentary: Attachment is a biological concept - a reflection on Fearon et al. (2014). Journal of Child Psychology and Psychiatry, 55: 1042-1043. doi:

10.1111/jcpp. 12301

Saltaris, C. (2002). Psychopathy in juvenile offenders: Can temperament and attachment be considered as robust developmental precursors? Clinical Psychology Review, 22(5), 729-752. doi: 10.1016/s0272-7358(01)00122-2

Savard, C., Brassard, A., Lussier, Y., \& Sabourin, S. (2015). Subclinical psychopathic traits and romantic attachment in community couples: A dyadic approach. Personality and Individual Differences, 72, 128-134. doi: 10.1016/j.paid.2014.08.014 
Sherman, E. D., \& Lynam, D. R. (2017). Psychopathy and low communion: An overlooked and underappreciated core feature. Personality Disorders: Theory, Research, and Treatment, 8(4), 309-318. doi: 10.1037/per0000203

Sullivan, H. S. (1953). The interpersonal theory of psychiatry. New York, NY: Norton.

Thomas, J., Newman, M., \& Oliver, S. (2013). Rapid evidence assessments of research to inform social policy: taking stock and moving forward. Evidence \& Policy: A Journal of Research, Debate and Practice, 9(1), 5-27. doi: 10.1332/174426413x662572

Ullrich, S., Farrington, D. P., \& Coid, J. W. (2008). Psychopathic personality traits and lifesuccess. Personality and Individual Differences, 44, 1162-1171. doi: 10.1016/j.paid.2007.11.008

Viding. E., Blair., R. J. R., Moffitt, T. R., Plomin, R. (2005). Evidence for substantial genetic risk for psychopathy in 7 year olds. Journal of Child Psychology and Psychiatry, 46(6), 592-597. doi: 10.1111/j.1469-7610.2004.00393.x

Viding, E., Frick, P. J., \& Plomin, R. (2007). Aetiology of the relationship between callousunemotional traits and conduct problems in childhood. The British Journal of Psychiatry, 190(S49), s33-s38. https://doi.org/10.1192/bjp.190.5.s33

Viding, E., \& McCrory, E. J. (2018). Understanding the development of psychopathy: progress and challenges. Psychological medicine, 48(4), 566-577. doi:

$10.1017 / \mathrm{S} 0033291717002847$

Walsh, Z., Swogger, M. T., \& Kosson, D. S. (2009). Psychopathy and instrumental violence: Facet level relationships. Journal of Personality Disorders, 23(4), 416-424. doi: 10.1521/pedi.2009.23.4.416 
Figure 1. Abridged example of Genogram instructions

\section{Examiners introduction to participant}

We are going to complete four diagrams, which describe your relationships. I will show you an example of how these patterns may look. As we go through these diagrams we will be using the following symbols.
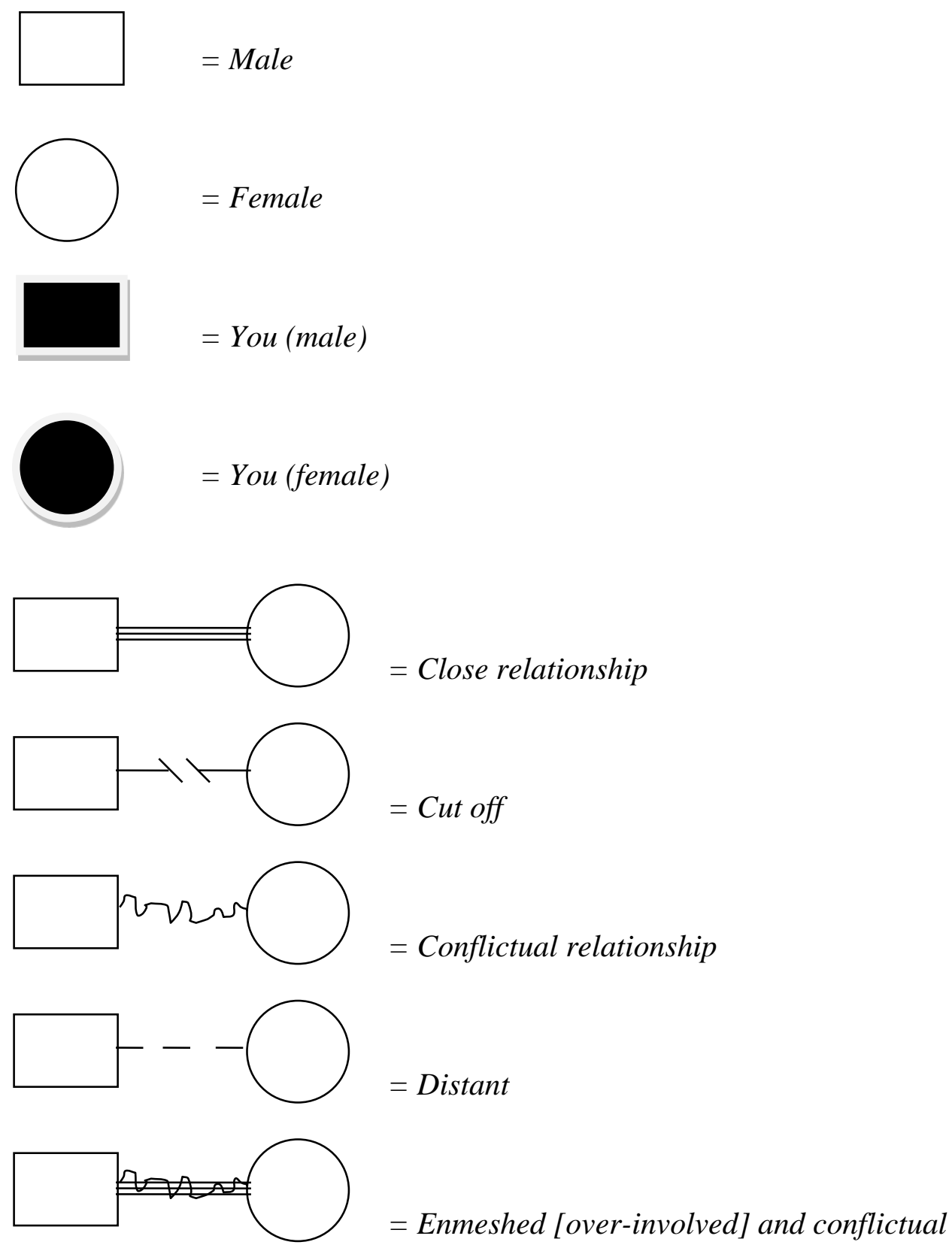

$$
\begin{aligned}
& \mathrm{X} X \mathrm{X} X \mathrm{X} X \mathrm{X} \mathrm{X} \quad \text { = You have been aggressive } \\
& <<<<<<\quad=\text { You have been exposed to aggression }
\end{aligned}
$$


Table 1

Means and Standard Deviations for PCL:SV Total, Factor 1, and Factor 2 Scores

\begin{tabular}{lcccccc}
\hline & \multicolumn{2}{c}{ PCL:SV Total } & \multicolumn{2}{c}{ PCL:SV Factor 1 } & \multicolumn{2}{c}{ PCL:SV Factor 2 } \\
& \multicolumn{2}{c}{ Scores } & \multicolumn{2}{c}{ Scores } & \multicolumn{2}{c}{ Scores } \\
& $M$ & $S D$ & $M$ & $S D$ & $M$ & $S D$ \\
\hline Group & 14.7 & 4.31 & 6.37 & 2.69 & 8.33 & 2.71 \\
\hline Students $(n=50)$ & 2.34 & 2.69 & 1.12 & 1.96 & 1.24 & 1.33 \\
Patients $(n=40)$ & & & & & & \\
\hline
\end{tabular}


Table 2

Means and Standard Deviations for the number and nature of relationships indicated in Genograms

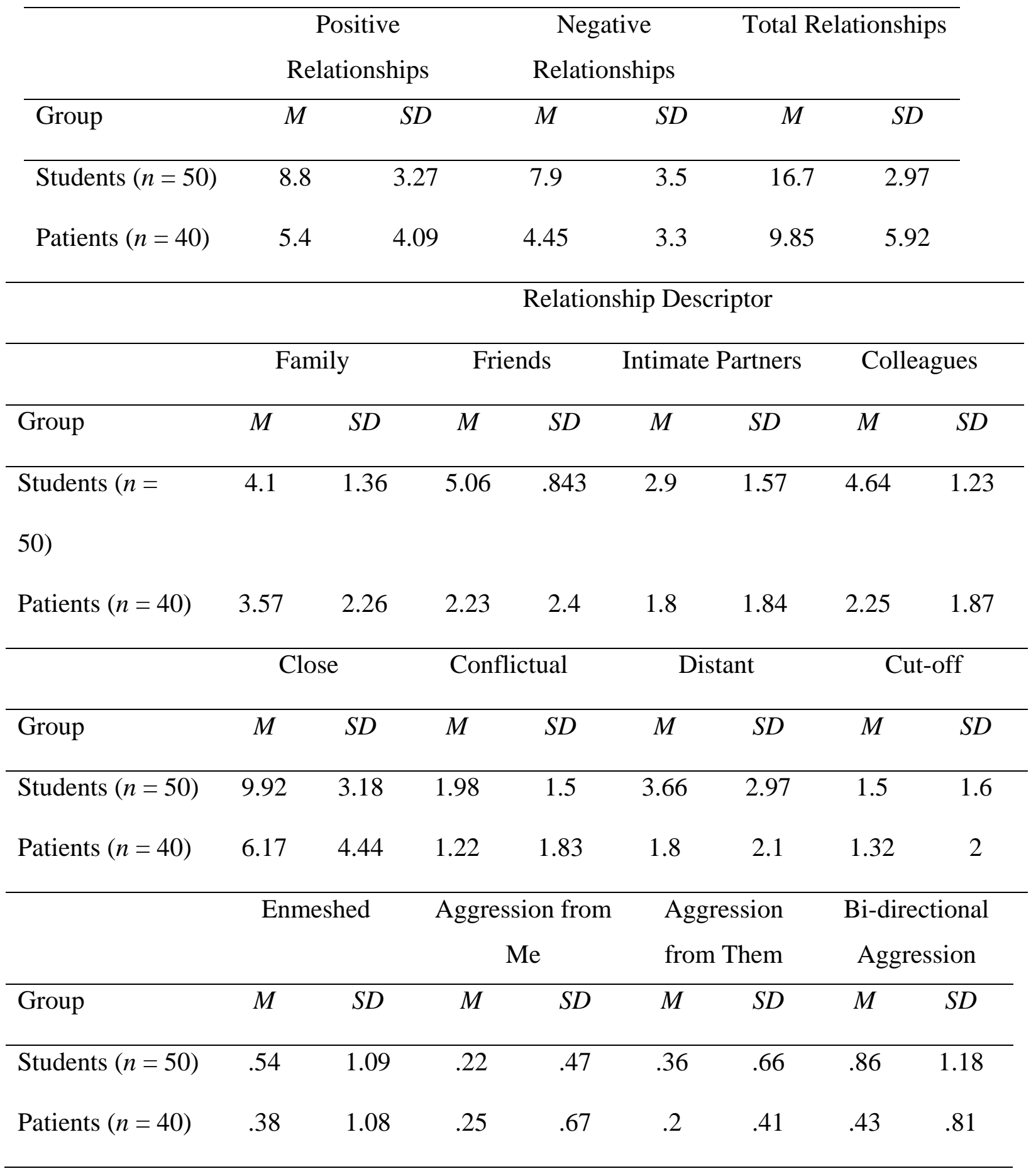


Table 3

Coded responses to ACL interview questions "How would you describe your relationships with others?" and "Who are the most important people in your life and why?"

Not psychopathic $(n=62) \quad$ Possibly psychopathic $(n=28)$

\begin{tabular}{|c|c|c|c|c|c|}
\hline & Response Category & Frequency $^{\mathrm{a}}$ & Percentage & Frequency & Percentage \\
\hline \multirow{10}{*}{ Quality } & Very good & 4 & $6.4 \%$ & 1 & $3.6 \%$ \\
\hline & Good & 29 & $46.8 \%$ & 6 & $21.4 \%$ \\
\hline & Strong & 6 & $9.7 \%$ & 3 & $10.7 \%$ \\
\hline & Close & 15 & $24.2 \%$ & 2 & $7.1 \%$ \\
\hline & $\mathrm{OK}$ & 8 & $12.9 \%$ & 9 & $32.1 \%$ \\
\hline & Shallow & 3 & $4.8 \%$ & 3 & $10.7 \%$ \\
\hline & Distant & 1 & $1.6 \%$ & 2 & $7.1 \%$ \\
\hline & Conflictual & 2 & $3.2 \%$ & 5 & $17.9 \%$ \\
\hline & Cut-off & 1 & $1.6 \%$ & 3 & $10.7 \%$ \\
\hline & Get on well with others & 24 & $38.7 \%$ & 8 & $28.6 \%$ \\
\hline \multirow{7}{*}{ Who } & Family & 33 & $53.2 \%$ & 11 & $39.3 \%$ \\
\hline & Parents & 25 & $40.3 \%$ & 13 & $46.4 \%$ \\
\hline & Siblings & 17 & $27.4 \%$ & 7 & $25 \%$ \\
\hline & Children & 4 & $6.4 \%$ & 5 & $17.9 \%$ \\
\hline & Grandparents & 6 & $9.7 \%$ & 2 & $7.1 \%$ \\
\hline & Intimate partner & 28 & $45.2 \%$ & 3 & $10.7 \%$ \\
\hline & Friends & 58 & $93.5 \%$ & 7 & $25 \%$ \\
\hline
\end{tabular}




\begin{tabular}{|c|c|c|c|c|c|}
\hline \multicolumn{2}{|c|}{ Hospital patients } & 4 & $6.4 \%$ & 5 & $17.9 \%$ \\
\hline & Hospital staff & 2 & $3.2 \%$ & 1 & $3.6 \%$ \\
\hline & No one & 1 & $1.6 \%$ & 2 & $7.1 \%$ \\
\hline & Myself & 1 & $1.6 \%$ & 2 & $7.1 \%$ \\
\hline & Support & 34 & $54.8 \%$ & 7 & $25 \%$ \\
\hline & Fun & 9 & $14.5 \%$ & 1 & $3.6 \%$ \\
\hline & Loyalty & 3 & $4.8 \%$ & 3 & $10.7 \%$ \\
\hline & Keep in contact & 5 & $8.1 \%$ & 6 & $21.4 \%$ \\
\hline & Love & 8 & $12.9 \%$ & 8 & $28.6 \%$ \\
\hline Why & History & 8 & $12.9 \%$ & 0 & $0 \%$ \\
\hline & Time together & 7 & $11.3 \%$ & 0 & $0 \%$ \\
\hline & Stability & 14 & $22.6 \%$ & 1 & $3.6 \%$ \\
\hline & Trust & 6 & $9.7 \%$ & 0 & $0 \%$ \\
\hline & Connection & 4 & $6.4 \%$ & 0 & $0 \%$ \\
\hline & All I have & 1 & $1.6 \%$ & 4 & $14.3 \%$ \\
\hline
\end{tabular}

Note. These ACL questions are grouped together because some of the same descriptors appeared in both sets of

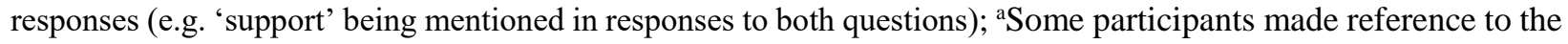
same descriptor in their responses to both questions. Therefore, 'frequency' does not indicate how many participants made reference to the descriptor, but rather how many times it was mentioned overall. Likewise, 'percentage' may not represent the percentage of the group who made reference to the descriptor. 


\section{Appendix A}

Studies included in the Rapid Evidence Assessment

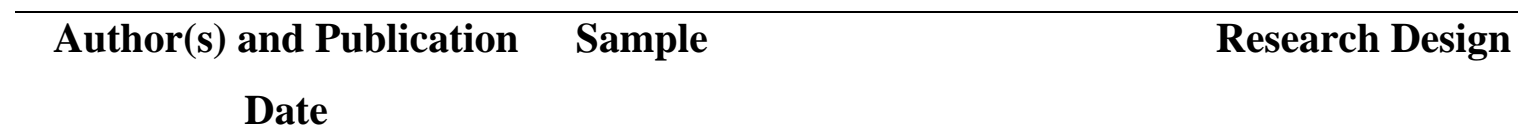

Blackburn, Logan, Renwick, Study 1: $n=168$ male forensic

\& Donnelly (2005)

Blackburn \& Maybury (1985) $n=60$ male forensic psychiatric

Brewer, Bennett, Davidson, Ireen, Phipps, Stewart-

Wilkes, \& Wilson (2018)

Christian, Sellbom, \&

Wilkinson (2017) patients (UK)

psychiatric patients (UK)

Study 2: $n=160$ participants from

Study 1

Study 1: $n=122$ female university students in heterosexual relationships (UK)

Study 2: $n=265$ females from the community in heterosexual relationships (UK)

Study 3: $n=240$ females from the community in heterosexual relationships (UK)

Study 1: $n=249$ members of the community (Australia)
Semi-structured interviews; review

of records; survey analysis (self-

report and other-report)

Survey analysis (self-report and other-report)

Survey analysis (self-report) 
Study 2: $n=292$ members of the

community (US)

Declercq, Willemsen, Audenaert, \& Verhaeghe $n=82$ male prisoners (Belgium) (2012)

Fix \& Fix (2015)

$n=111$ male undergraduate students (US)

Iyican \& Babcock (2018)

Jonason, Duineveld, \&

Middleton (2015)

Kardum, Hudek-Knezevic, Gračanin, \& Mehic (2017)

Lobbestael, Arntz, Voncken, \& Potegal (2017) $n=114$ heterosexual couples from the community (US)

$n=290$ members of the community (predominantly US)

Study 1: $n=1456$ members of the community (Croatia)

Study 2: $n=288$ heterosexual

couples from the community

Study 3: $n=100$ couples from Study

2

$n=91$ male members of the community (Netherlands and Germany)
(Croatia)
Semi-structured interviews and review of records

Survey analysis (self-report)

Survey analysis (self-report and other-report)

Survey analysis (self-report)

Survey analysis (self-report)

\author{
Survey anatysis (self-report)
}


Mager, Bresin, \& Verona

(2014)

Massar, Winters, Lenz, \&

Jonason (2017)

Rauthmann (2011)

Reidy, Wilson, Sloan, Cohn, Smart, \& Zeichner (2013)

Sherman \& Lynam (2017)

Walsh, Swogger, \& Kosson (2009) $n=250$ members of the community

with recent drug and/or violence

histories (US)

$n=347$ men and women from the

Survey analysis

community (predominantly US and

Netherlands)

$n=408$ university students (Austria) Survey analysis

$n=68$ male university students (US)

$n=195$ university students (US)

$n=248$ male prisoners (US)

Semi-structured interview;

institutional file trawl 